\title{
Surgical Outcome of Anterior Cervical Discectomy and Fusion (ACDF) with Autologous Bone Graft from Iliac Bone and Miniplate Application Over It
}

\author{
RIAZ-UR-REHMAN, ${ }^{1}$ MUHAMMAD NAWAZ KHAN ${ }^{2}$ \\ SAJJADULLAH, ${ }^{1}$ ATTIYA NASIR, ${ }^{2}$ HANIF-UR-RAHMAN ${ }^{2}$ \\ ${ }^{1}$ Department of Neurosurgery, Lady Reading Hospital, Peshawar, Pakistan \\ ${ }^{2}$ Hayatabad Medical Complex Peshawar, Pakistan \\ DOI: https://doi.org/10.36552/pjns.v23i3.362
}

\begin{abstract}
Objectives: To know the surgical outcome of ACDF with autologous bone graft from iliac bone and miniplate application over it.

Materials and Methods: This prospective study was conducted in the Department of Neurosurgery, Hayatabad Medical Complex and Lady Reading Hospital Peshawar from $1^{\text {st }}$ June 2017 to 31 December 2018. Only those patients having prolapsed intervertebral cervical discs or cervical stenosis were included while those with multiple level involvement, trauma, fracture and previously operated patients for any cervical pathology were excluded. Pre-op and postoperative data were documented. For all patients, tricortical iliac bone autograft and rigid plate instrumentation was used to optimize fusion cervical collar was not used post op. Acquired data were analyzed with SPSS $v 20$.
\end{abstract}

Results: Total 83 patients fulfilled the inclusion criteria and enrolled in the study. Out of these, 48 patients were males and 35 were females. The age range was from 17 to 63 with a mean age 52 years \pm 2.5 .The C5 - C6 was the commonest site for fusion C6 - C7, C3 - C4 and C4-C5 were less common. Odom's criteria was applied to determine the outcome of the procedure. Excellent results were noted in 70 (82\%). Ten (12.05\%) patients had good results. Two patients $(2.40 \%)$ had fair and one patient (1.20\%) had poor outcome. A successful reported fusion was achieved in 80 (96.38\%) patients. Surgical site infection was noted in 3(3.61\%) patients and screw breakage was seen in one (1.20\%) patient.

Conclusion: The ACDF with the tricortical iliac bone autograft and mini plate application is the choice treatment in appropriately selected patients. It increases chances of fusion and abates the need for post op cervical collar. There is some risk of adjacent level disease but high cost of artificial disc replacement renders it unaffordable for our patients.

Key Words: Cervical radiculopathy, ACDF, Miniplate, Outcome. Iliac bone graft.

Abbreviations: ACDF: Anterior Cervical Discectomy and Fusion. VAS: Visual Analogue Score.

\section{INTRODUCTION}

Cervical radiculopathy is a common condition, the prevalence is $3.5 / 1,000$ and annual incidence $83 / 100,000 .^{1}$ Radiculopathy is caused by various clinical conditions like prolapsed intervertebral disc, stenosis, and trauma or sometime by tumors and even spinal instability. ${ }^{2}$ Cervical spondylosis however, is the commonest cause followed by disc herniation ${ }^{3}$.Prolapsed disc mostly occurs in a relatively younger population in age range from 30 to 50 years. ${ }^{4}$ Most commonly affected level of disc herniation is C5-C6 level. ${ }^{5}$ Majority of cervical prolapsed discs can be treated conservatively. However, some selected cases requires surgery, which can be done in various ways 
both from anterior and posterior. ${ }^{6,7,8,9,10}$

Fusion after anterior cervical discectomy has given excellent outcome in reference to patient relief from radiculopathy pain in $94 \%$ patients. ${ }^{11}$ However, there can be nonunion and graft dislodgment if ACDF is being done without plating. ${ }^{12}$ So to illuminate these risks putting a mini plate over the graft will solve most of these grafts related problems. We present our study and share our experience of surgical outcome of ACDF with autologous bone graft from iliac bone and miniplate application over it in terms of efficacy and symptoms relief and graft fusion and complications.

\section{MATERIALS AND METHODS}

\section{Study Design}

This prospective study was conducted in the Department of Neurosurgery, Hayatabad Medical Complex and Lady Reading Hospital Peshawar from $1^{\text {st }}$ June 2017 to 31 December 2018.

\section{Inclusion Criteria}

All the patients were consented before their registration to the study and approval was taken from hospital ethical review committee. Only those patients having a single level prolapsed inter vertebral cervical discs were enrolled in the study in whom conservative management was failed.

\section{Exclusion Criteria}

Exclusion criteria was multiple levels involvement, trauma, fracture and previously operated patients for any cervical pathology.

\section{Data Collection}

Pre-op detailed history, clinical examination findings, X-ray cervical spine and MRI cervical spine were done and documented for all the patients in database before surgery. For all patients, tricortical iliac bone autograft and rigid plate instrumentation was used to optimize fusion. All the patients were operated by the primary author in the same way to minimize bias. All patients were operated in supine position under general anesthesia. Surgical level was confirmed with image intensifier. Autologous bone graft was taken from the ipsilateral side iliac bone. Cervical collar was not used post op.

Various outcomes questionnaires were documented preoperatively and at postoperative intervals based on Odom's criteria. Outcomes were also assessed and measured using a neck and arm pain with visual analog scale Fusion was assessed with dynamic cervical $\mathrm{x}$ rays and $\leq 1 \mathrm{~mm}$ movement at the required site was considered as fused at third month follow up visit.

\section{Data Analysis}

SPSS version 20 was used for analysis and $\mathrm{P}>0.05$ was considered significant.

\section{RESULTS}

\section{Gender Distribution}

Total 83 patients fulfilled the inclusion criteria and enrolled in the study. Out of these, 51 patients were males and 32 were females. The age range was from 17 to 63 with mean age 52 years \pm 2.5 .

Gender distribution is shown in table 1.

Table 1: Gender distribution.

\begin{tabular}{|l|c|c|}
\hline Gender & No of Patient & Percent \\
\hline Men & 51 & $61.45 \%$ \\
\hline women & 32 & $38.55 \%$ \\
\hline Total & 83 & $100 \%$ \\
\hline
\end{tabular}

\section{Vertebral Level Involved}

The C5-C6 was the commonest site for fusion, the least common sites were C6 - C7, C3 - C4 and C4 $\mathrm{C} 5$ as shown in table 2 . We used titanium miniplates with locking screws in all cases.

Table 2: Vertebral levels involvement.

\begin{tabular}{|l|c|c|}
\hline Involved Disc & No. of Patients & Percentage \\
\hline C3 - C4 & 7 & $8.43 \%$ \\
\hline C4 - C5 & 4 & $4.82 \%$ \\
\hline C5 - C6 & 56 & $67.47 \%$ \\
\hline C6- C7 & 15 & $18.07 \%$ \\
\hline C7 - T1 & 1 & $1.20 \%$ \\
\hline
\end{tabular}

\section{Outcome}

Odom's criteria was utilized to determine the 
results of the procedure. Excellent results were noted in $70(82 \%)$. Ten $(12.05 \%)$ patients had good results. Two patients $(2.40 \%)$ had fair and one patient $(1.20 \%)$ had a poor outcome.

Table 3: Clinical Outcome.

\begin{tabular}{|l|c|c|}
\hline Outcome Group & No. of Patients & Percentage \\
\hline Excellent & 70 & $82 \%$ \\
\hline Good & 10 & $10.05 \%$ \\
\hline Fair & 2 & $2.40 \%$ \\
\hline Poor & 1 & $1.20 \%$ \\
\hline
\end{tabular}

Successful reported a fusion was achieved in 80 $(96.38 \%)$ patients. Surgical site infection was noted in $3(3.61 \%)$ patients and screw breakage was seen in one $(1.20 \%)$ patient.

\section{DISCUSSION}

The objective of putting graft into disc space is to have solid bone fusion and achieve alignment. Addition of plate prevent graft dislodgement and graft collapse, decrease the need for external orthosis and hence early mobilization. ${ }^{13,14,15}$ In this study only single level ACDF has been done and will be discussed. Wang et $\mathrm{al}^{16}$ conducted a study on multiple level ACDF. They achieved fusion rates of $91.7 \%$ in patient with no plating and $95.5 \%$ were achieved with plating. They further proved in his study that results were excellent in $91 \%$ of cases with plating in comparison to $88 \%$ of the cases without use of plate. ${ }^{16}$

In another study, Kaiser et $\mathrm{al}^{17}$ used single level anterior cervical discectomy and fusion in 157 cases with use of plate and compared the results with a cohort of 242 non-plated patients. He found a fusion rate of $90 \%$ in non-instrumented patients and $96 \%$ in plated patients. In one local study conducted my Khan et al, a fusion rate of $96.93 \%$ for one level anterior cervical discectomy and fusion was achieved. ${ }^{18}$ In the present study, the fusion rate of $96.38 \%$ is in line with the Wang et al. work and other local and international studies. Hence, the above results prove that fusion rates are improved by the use of mini plates while performing one level cervical discectomy.

The results of present studies show the excellent results in $82 \%$ and good results in $12.05 \%$ patients. Khan et $\mathrm{al}^{18}$ study results are more or less the same which suggests ACDF is the choice treatment in relieving radicular pain. Various studies reveal various complication rates in various parts of the world. Infection is one relatively common complication in our part of the world. The infection rate of $3.61 \%$ can be seen in this study. However, the comparable results were reported in Khan et $\mathrm{al}^{18}$ study as well, which suggests this is quite an acceptable range.

After analyzing the overall results of the study population in terms of clinical outcome and complication rate. We believe ACDF with titanium miniplates application is the most appropriate treatment option due to overcast effectiveness and very little surgical time prolongation. However, our study has a limitation of long term follow up. Bigger prospective RCT studies are needed to prove these results.

\section{CONCLUSION}

ACDF with the tricortical iliac bone autograft and mini plate application is the choice treatment in appropriately selected patients .It increases chances of fusion and abates the need for post op cervical collar. There is some risk of adjacent level disease but high cost of artificial disc replacement renders it unaffordable for our patients.

\section{Additional Information}

Disclosures: Authors report no conflict of interest.

Human Subjects: Consent was obtained by all patients/ participants in this study.

Conflicts of Interest:

In compliance with the ICMJE uniform disclosure form, all authors declare the following:

Financial Relationships: All authors have declared that they have no financial relationships at present or within the previous three years with any organizations that might have an interest in the submitted work.

Other Relationships: All authors have declared that there are no other relationships or activities that could appear to have influenced the submitted work.

Address for correspondence: M. Nawaz Khan

Specialist Registrar Neurosurgery Hayatabad Medical Complex Peshawar Email:dr.nawaz2009@yahoo.com

\section{REFERENCES}

1. Todd AG. Cervical spine: degenerative conditions. Current Reviews in Musculoskeletal Medicine, 2011; 4: $168-174$. 
2. Caridi JM. Cervical radiculopathy: a multicentre review. HSS Journal. 2012; 7: 266-273.

3. Radhakrishnan K, Litchy W J, O'Fallon WM, Kurland LT. Epidemiology of cervical radiculopathy: a population-based study from Rochester Minnesota, 1976 through 1990.Brain, 1994; 117: 325-335.

4. Litchy W J, Radhakrishnan K, O'Fallon WM, Kurland LT. Epidemiology of cervical radiculopathy: a population-based study from Rochester Minnesota, 1976 through 1990. Brain, 1994; 117: 325-335.

5. Caridi JM, Pumberger M, Hughes AP. Cervical radiculopathy: a review. HSS Journal, 2011; 7: 265272.

6. Pumberger M, Caridi JM, Hughes AP. Cervical radiculopathy: a review. HSS Journal, 2011; 7: 265272.

7. Todd AG. Cervical spine degenerative conditions. Current Reviews in Musculoskeletal Medicine, 2011; 4 : 168-174.

8. Akhavan-Sigari R, Rohde V, Alaid A. Cervical spinal canal stenosis and central disc herniation C3 C4 in a man with primary complaint of thigh pain. Journal of Neurological Surgery Reports, 2013; 74: 101-104.

9. Clavenna A, Dossett AB. Anterior cervical diskectomy and fusion. Operative Techniques in Sports Medicine, 2005; 13: 90-95.

10. Lees F, Turner JW. Natural history and prognosis of cervical spondylosis. British Medical Journal, 1963; 2:
1607-9.

11. Saal JS, Saal JA, Yurth EF. Nonoperative management of herniated cervical intervertebral disc with radiculopathy. Spine, 1996; 21: 1877-83.

12. Zdeblick T, Ducker TB. The use of freeze-dried allograft bone for anterior cervical fusions. Spine, 1991; 16: 726-9.

13. Paramore CG, Dickman CA, Sanntag VK. Radiographic and clinical follow up review of Casper plates in 49 patients. J Neurosurg. 1996; 84: 957-61.

14. Barnes B, Hiad RWJ, Rodts GEJ, Subach BR, Kaiser MG. Early results using the Atlantis anterior cervical plate system. Neurosurg Focus, 2002; 12: 13-16.

15. Orzco RT. Osteossintese en las fractures de raquis cervical. Rev Orthop Traumatol. 1977; 14: 285-8.

16. Wang JC, McDonough PW, Endow KK, Delamarter RB. Increased fusionrates with cervical platting for two-level anterior cervical discectomy and fusion. Spine, 2000; 25: 41-5.

17. Kaiser MG, Haid RWJ, Subach BR, Barnes B, Roodts GEJ. Anterior cervical platting enhances arthodesis after discectomy and fusion with cortical allograft. Neurosurgery, 2001; 50: 229-36.

18. Khan I, Burhan M. Titanium miniplates use: a simple and effective method of preventing bone graft dislodgment in anterior cervical discectomy and fusion. Rawal Med J. 2009; 34 (1): 7-

\begin{tabular}{|c|c|c|c|}
\hline \multicolumn{4}{|c|}{ AUTHORSHIP AND CONTRIBUTION DECLARATION } \\
\hline Sr.\# & Author's Full Name & Intellectual/Contribution to Paper in Terms of: & \\
\hline 1. & $\begin{array}{l}\text { Riaz-ur-Rehman } \\
\text { (Main/Principal Author). }\end{array}$ & $\begin{array}{l}\text { 1. Proposed topics and Basic Study Design, } \\
\text { methodology. }\end{array}$ & $\begin{array}{l}\text { Signature by } \\
\text { the author(s) }\end{array}$ \\
\hline 2. & $\begin{array}{l}\text { Muhammad Nawaz Khan } \\
\text { (2nd Author) }\end{array}$ & 2. Data collection and calculations & \\
\hline 3. & $\begin{array}{l}\text { SajjadUllah } \\
\text { (3rd Author) }\end{array}$ & $\begin{array}{l}\text { 3. Analysis of data and interpretation of results } \\
\text { etc. }\end{array}$ & \\
\hline 4. & $\begin{array}{l}\text { Attiya Nasir } \\
\text { (4th Author) }\end{array}$ & 4. Study Design and methodology & $A m$ \\
\hline 5. & $\begin{array}{l}\text { Hanif-ur-Rahman } \\
\text { (6th Author) }\end{array}$ & 5. Literature review and manuscript writing & \\
\hline
\end{tabular}

Date of Submission: 02-06-2019

Date of Revision: 15-07-2019

Date of Online Publishing: 25-09-2019

Date of Print: 30-09-2019 